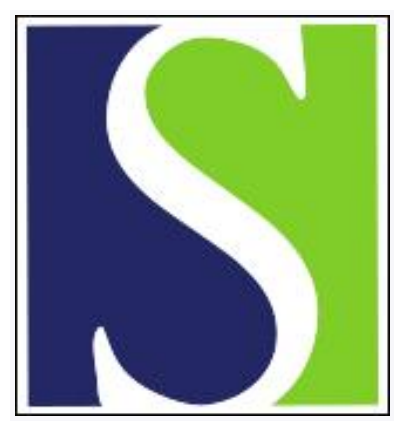

Scand J Work Environ Health 2006;32(2):99-108

https://doi.org/10.5271/sjweh.985

Issue date: 30 Apr 2006

Natural course of nontraumatic rotator cuff tendinitis and shoulder symptoms in a working population

by Silverstein BA, Viikari-Juntura E, Fan ZJ, Bonauto DK, Bao S, Smith C

Affiliation: Safety \& Health Assessment and Research for Prevention (SHARP), Washington State Department of Labor \& Industries, PO Box 44330, Olympia, Washington 98504-4330, USA. Silb235@Ini.wa.gov

The following articles refer to this text: 2010;36(3):185-187;

2010;36(5):384-393; 2011;37(2):81-84; 2011;37(6):512-524;

2011;37(6):502-511; 2012;38(5):436-446; 2012;38(6):568-576

Key terms: active worker; incidence; prevalence; rotator cuff tendinitis; shoulder symptom; working population

This article in PubMed: www.ncbi.nlm.nih.gov/pubmed/16680380 


\title{
Natural course of nontraumatic rotator cuff tendinitis and shoulder symptoms in a working population
}

\author{
by Barbara A Silverstein, PhD, ${ }^{1}$ Eira Viikari-Juntura, DMedSci, ${ }^{2}$ Z Joyce Fan, PhD, ${ }^{1}$ Dave K Bonauto, MD, ${ }^{1}$ \\ Stephen Bao, PhD, ${ }^{1}$ Caroline Smith, $B A^{1}$
}

\begin{abstract}
Silverstein BA, Viikari-Juntura E, Fan ZJ, Bonauto DK, Bao S, Smith C. Natural course of nontraumatic rotator cuff tendinitis and shoulder symptoms in a working population. Scand J Work Environ Health 2006;32(2):99108.
\end{abstract}

Objectives This study assessed the prevalence, incidence, and persistence of nontraumatic rotator cuff tendinitis and shoulder symptoms over a 1-year period in a working population and the predictive value of symptoms and physical findings.

Methods A 1-year prospective study of 436 active workers was conducted at 12 different worksites. Detailed health interviews, psychosocial questionnaires, and physical examinations were conducted at baseline and again after 1 year, with shorter evaluations at 4 and 8 months. Individual observed exposure assessment of shoulder posture, arm-hand activity, and hand forces was conducted.

Results The prevalence of rotator cuff tendinitis at baseline was 7.6\% [95\% confidence interval (95\% CI 5.1$10.1 \%)$ ] for the right and $4.8 \%$ (95\% CI 3.0-7.0\%) for the left, compared with shoulder symptoms of $18.6 \%$ (95\% CI 14.9-22.3\%) (right) and 11.2\% (95\% CI 8.2-14.2\%) (left). The incidence of rotator cuff tendinitis was 5.5\% (95\% CI 2.8-6.8\%) and 2.9\% (95\% CI 1.0-3.8\%), respectively. Higher proportions of participants with current symptoms or physical findings at baseline became clinical cases after 1 year than those without symptoms or findings. The 1-year persistence of clinical case status was 31.3\% (95\% CI 26.9-35.7\%) (right) and $31.6 \%$ (95\% CI 27.2-36.0\%) (left). There were significant differences at baseline between the asymptomatic participants and the clinical cases with respect to physical health on the 12-item Short-form Health Survey $(\mathrm{P}=0.0002)$, the perception of general health $(\mathrm{P}=0.0027)$, and the frequency of high hand force exposure $(\mathrm{P}=0.0177)$.

Conclusions Considerable movement occurs between different stages of shoulder problems. Symptoms and physical findings alone appear to predict clinical case status within 1 year. Frequent follow-up is necessary to capture changes in health and exposure status in prospective studies.

Key terms active worker; incidence; prevalence.

The prevalence of shoulder pain is high in the general adult population, ranging from 30\% in Manchester England (1) to $34 \%$ in the Mini-Finland (2) population. Shoulder impairment was observed in $9 \%$ of the participants in the Mini-Finland survey population. The prevalence of clinically diagnosed rotator cuff tendinitis was $2.0 \%$ in the Finnish Health 2000 population (3). A 3year follow-up of the Manchester population showed that $54 \%$ were still symptomatic. In working populations, the annual incidence of shoulder symptoms ranges from $14 \%$ to $18 \%$ (4-8).
In Washington state, $3.3 \%$ of all workers' compensation claims are due to a nontraumatic shoulder disorder with an average annual incidence rate of 3.7 per 1000 full-time equivalent employees, an average cost of USD 10 160, and lost time of 195 days per claim (9). The incidence of claims due to nontraumatic rotator cuff syndrome is 1.6 per 1000 full-time equivalent employees with the average cost of USD 21872 and 260 lost days per compensable claim. Lost production time (absence and reduced performance) among workers with musculoskeletal pain in the United States averages more

1 Safety \& Health Assessment and Research for Prevention (SHARP), Washington State Department of Labor \& Industries, Olympia, Washington, United States.

2 Finnish Institute of Occupational Health, Helsinki, Finland.

Reprint requests to: Dr B Silverstein, Safety \& Health Assessment and Research for Prevention (SHARP), Washington State Department of Labor \& Industries, PO Box 44330, Olympia, Washington 98504-4330, USA. [E-mail: Silb235@lni.wa.gov] 
than 5 hours per week (10). Mechanical factors (repetitive movements, vibration, and duration of employment) and psychosocial factors appear to increase the risk of shoulder pain although the effects of individual psychosocial factors are not consistent across studies (11). Increasing age, but neither working in a repetitive work category nor high psychosocial demands predicted slowed recovery among industrial and service workers with shoulder pain and clinical signs of shoulder tendinitis (12).

Because the incidence and costs of shoulder disorders are high, a better understanding of the natural course of these disorders in a working population can better target both primary and secondary prevention efforts. The aim of this study was (i) to assess the prevalence, incidence and persistence rates of nontraumatic rotator cuff tendinitis and shoulder symptoms over a 1year period in a working population and (ii) to study whether shoulder symptoms and physical examination findings alone predict the clinical case status of rotator cuff tendinitis.

\section{Study population and methods}

\section{Design}

We conducted a prospective cohort study of rotator cuff tendinitis and shoulder symptoms among full-time employees in 12 different manufacturing and health care facilities in the state of Washington from 2001 to 2004. A workplace walk-through was conducted by study ergonomists to categorize jobs according to the threshold limit value of the American Conference of Governmental Industrial Hygienists (ACGIH) for hand activity level (13). Facilities with at least 20 employees in three of six force (high-low) repetition (high-medium-low) categories were eligible for inclusion. Those eligible and willing to participate in health assessment data collections completed an informed consent form approved by the Washington State Institutional Review Board and entered the baseline data collection. At baseline and 1year visits, we collected information on each worker's work and health assessment, physical examination (blinded to work and health status and physical exposure), and physical exposure assessment (blinded to health status). We also collected information on symptoms during 4- and 8-month visits. If there was a change in symptom status (either more severe or symptoms disappearing), the shoulder-neck examination was repeated. If a change in job was reported, a re-evaluation of the job tasks was repeated. Exclusion criteria included working part-time or with temporary status and work- ing in mobile jobs such as forklift driving or in jobs with more than four tasks due to resource constraints. Individual health assessment was conducted during workhours by the health team (physician, nurse, and physiotherapist) blinded to exposure category and health history. The exposure assessment team (blinded to health status) collected individual exposure assessment data at baseline and at follow-up if there were job changes.

\section{Study population}

Most of the participants (86.5\%) worked in the manufacturing sector (electronics, medical or exercise equipment, windows, kitchen cabinets, sawmill, and plywood mills). At baseline, 733 workers (64.5\% of those eligible) participated in the study. The reasons for nonparticipation were mostly related to the production process. We excluded 35 workers who reported, either at the baseline or at the 1-year follow-up, that their shoulder problem started as the result of a sudden injury (26 on the right, 14 on the left, 5 on both sides), leaving 698 participants in the study.

At the 1-year follow-up, 436 (62.5\% of those at baseline) were available for study. Many of those lost to follow-up ( $\mathrm{N}=262)$ were laid off (23.7) or had employment terminated (26.3\%) during the economic recession, while $5.3 \%$ of the participants had left the company for another job, and $9.5 \%$ were no longer interested in participating. The remaining $34.4 \%$ were unavailable due to vacation, sick leave, or an unknown reason. Two participants $(0.8 \%)$ were deceased. A higher percentage of those lost to follow-up tended to be in the high lifting group for both the right and left shoulders (20.2\% versus $13.5 \%$ time-weighted and $25.8 \%$ versus $21.4 \%$ high peak-lifting force on the right). While those lost to follow-up had higher overall psychosocial strain, there were no significant differences in the baseline SF12 scores (see the Health Assessment section) for mental $(\mathrm{P}=0.86)$ or physical $(\mathrm{P}=0.07)$ health between those lost to follow-up and those who remained in the study. A review of workers' compensation data did not show that a larger portion of those lost to follow-up filed workers' compensation claims than those remaining at the workplace. Table 1 presents the demographic characteristics of the study population, including those lost to follow-up. The participants who were lost to followup were younger and had fewer work years in their current jobs than those who remained in the study.

\section{Health assessment}

Information on individual factors (age, gender, race, and education), a detailed structured health history (diseases diagnosed by a physician and traumatic injuries), job 
history (current job, time on job, and change in jobs), and the presence of musculoskeletal symptoms was collected by trained interviewers. The participants were screened for symptoms (using a body map) for any pain or discomfort in the previous 12 months that lasted at least 1 week or occurred more than three times. For the participants with pain or discomfort, a specific body map was used to ascertain a more precise location of symptoms. Information on the onset, duration, frequency, severity, last occurrence, treatment, and whether there was interference with workpace or the quality and number of lost workdays was obtained. Professional interpreters were available to assist those whose primary language was not English.

A self-administered psychosocial questionnaire was completed which included job demands, decision latitude, job security, job satisfaction (14), social support (15), and the 12-item Short-form Health Survey (SF-12) (16). The questionnaire was available in multiple languages. Assistance was provided for the participants with reading difficulties.

An examiner who was blinded to both exposure status and the interview data completed a brief physical examination of the shoulders and neck of all of the participants at baseline and again after 1 year. If there was a change in the symptom status at 4 or 8 months, the shoulder-neck examination was repeated.

\section{Case definitions}

To be classified as a clinical case of nontraumatic rotator cuff tendinitis, a participant had to have at least one positive shoulder test [resisted abduction, internal rotation, or external rotation or painful arc (17)] and meet both of the following symptom criteria: (i) shoulder pain or burning in the past 12 months occurring more than three times or lasting more than 1 week, and (ii) shoulder pain or burning present in the 7 days prior to the assessment

To follow the natural course, we classified the participants into five categories according to symptoms and physical findings (table 2).
Table 1. Demographic characteristics of the participants.

\begin{tabular}{lccc}
\hline Characteristic & $\begin{array}{c}\text { Participants } \\
\text { at } \\
\text { baseline } \mathrm{a,b} \\
(\mathrm{N}=698) \\
(\%)\end{array}$ & $\begin{array}{c}\text { Participants } \\
\text { attending } \\
\text { one year } \\
\text { follow-up } \mathrm{a}^{\mathrm{a} b} \mathrm{~b} \\
(\mathrm{~N}=436)(\%)\end{array}$ & $\begin{array}{c}\text { Participants } \\
\text { lost to } \\
\text { follow-up a,b } \\
(\mathrm{N}=262) \\
(\%)\end{array}$ \\
\hline Male & 52.6 & 49.3 & 58.0 \\
Race & & & \\
White & 58.9 & 57.6 & 61.1 \\
Asian & 18.6 & 20.2 & 16.0 \\
Hispanic & 13.0 & 13.0 & 13.0 \\
Other & 9.5 & 9.2 & 9.9 \\
With at least high & 83.7 & 83.5 & 84.0 \\
school education & & &
\end{tabular}

a Median age: 40.0 years for participants at baseline, 41.0 years for those attending 1-year follow-up, and 37.6 years for those lost to follow-up.

b Median years in current job: 2.3 years for participants at baseline, 2.5 years for those attending the 1-year follow-up, and 1.9 for those lost to follow-up.

With permission of the participants, individual claims data were extracted from the workers' compensation system for evidence of nontraumatic shoulder disorders between 2000 and 2003 to compare with the findings of the study case definition.

\section{Physical exposure assessment}

In order to assure variability in exposure, we used the ACGIH hand activity level (HAL) during a workplace walkthrough to categorize participants into six preliminary exposure categories.

Individual exposure assessment included videotaping the participants from two angles for a synchronized viewing of the tasks to estimate exposures to high forces, postures, and repetitive movement. High forces perceived by the ergonomist to be equal to or greater than $8.9 \mathrm{~N}$ of pinch or object weight (corresponding to $2 \mathrm{lb}$ or $0.9 \mathrm{~kg}$ ), or $44.1 \mathrm{~N}$ of power grip, object weight or push-pull force (corresponding to $10 \mathrm{lb}$ or $4.5 \mathrm{~kg}$ ) were measured at the task level. Videotapes of the tasks were time-studied using Multimedia Media Task Analysis (MTVA) software (18). Single task jobs were videotaped

Table 2. Classification of the participants by diagnostic criteria. $(+=$ positive,$-=$ negative,$\cdot=$ either positive or negative)

\begin{tabular}{|c|c|c|c|c|c|}
\hline Classification & $\begin{array}{l}\text { No symptoms a } \\
\text { or physical } \\
\text { findings }\end{array}$ & $\begin{array}{c}\text { Physical findings } \\
\text { without } \\
\text { symptoms }^{\text {b }}\end{array}$ & $\begin{array}{l}\text { Past } \\
\text { symptoms }\end{array}$ & $\begin{array}{l}\text { Current } \\
\text { symptoms }\end{array}$ & $\begin{array}{l}\text { Clinical } \\
\text { case }\end{array}$ \\
\hline $\begin{array}{l}\text { Shoulder pain or burning in the past } 12 \text { months } \\
\text { occurring more than } 3 \text { times or lasting more than } 1 \text { week }\end{array}$ & - & - & + & + & + \\
\hline $\begin{array}{l}\text { Shoulder pain or burning present in the } \\
7 \text { days prior to the assessment }\end{array}$ & - & - & - & + & + \\
\hline Shoulder test on physical examination & - & + & - & - & + \\
\hline
\end{tabular}

a No symptoms fulfilling both symptom criteria; a small number of participants (2 right, 0 left side at baseline; 3 right, 2 left side at 1-year follow-up) had symptoms in the 7 days prior to the assessment but did not fulfill the 12-month frequency or duration criterion.

${ }^{b}$ No symptoms fulfilling both symptom criteria; a small number of participants (4 right side, 5 left side at baseline; 3 right side, 1 left side at 1 -year followup) had symptoms that fulfilled only the 12-month frequency or duration criterion. 
for 15 minutes. Multi-task cyclic jobs were videotaped for each task. Noncyclic task jobs were videotaped at three different times during the day to capture different tasks. The frequency and duration of each high force exertion were identified. Task distribution information (percentage of time each task took in the job) was obtained in interviews of the workers or the supervisors. They were used to develop time-weighted estimates for each task and were translated into the percentage of the shift with high force for the left and right hand and the frequency of high force per minute over all of the tasks. The calculation of the percentage of the shift for the various high forces was done for lifting. Since all of these variables showed a highly skewed distribution and some of our diagnostic groups were small, we dichotomized the variables according to published guideline limits, as in appendix B of the Washington State ergonomics rule (19). The cut point for the high frequency of high force exertions of 6/minute, upper-arm abduction $>60$ degrees (20), for more than $7.0 \%$ of the time, upper-arm flexion $>45$ degrees (21-22) for more than $4.0 \%$ of the time, hand exertion duration $\geq 6$ seconds, and hand exertion frequency of 20 /minute was close to the 75 th percentile value of these exposure variables.

\section{Analysis}

Because the focus of this paper is to show the clinical course of nontraumatic shoulder disorders in working populations, descriptive statistics have been presented by shoulder and clinical category. Psychosocial factors were dichotomized on the basis of median scores. The analyses were conducted using SAS (version 9.1) (23) statistical software. The Wilcoxon rank sum test or Kruskal-Wallis test was used to assess the differences between the clinical categories for continuous variables, and chi-square tests were used for the categorical variables.

\section{Results}

\section{Demographic characteristics, physical exposure and psychosocial factors by shoulder status at baseline}

For conciseness of presentation, the focus in the results is primarily on the right shoulder. The demographic characteristics of the study population are shown in table 3 according to the right shoulder status at baseline. Of the 436 baseline participants available after 1 year, the female participants reported a greater proportion of symptoms but showed a lower proportion of physical findings and clinical cases than the men. Compared with the clinical cases, the participants without signs or symptoms (noncase) did not differ in gender or race distribution or education level, but were younger by 5 years and had fewer years in their current job.

Men and women were not evenly distributed in the initial physical workload categories with a higher percentage of men in the high force-low repetitive jobs $(80.8 \%)$ and a higher percentage of women in low force-high repetitive jobs $(59.4 \%, \mathrm{P}=0.0027)$. No significant difference in the original job categories was observed among the clinical cases when compared with the rest of the study population $(\mathrm{P}=0.61)$. There were significant differences at baseline between the asymptomatic participants and clinical cases with respect to the frequency of high hand-force exposure $(\mathrm{P}=0.0178)$. The no symptoms, no physical findings groups $(\mathrm{N}=263)$ had a lower proportion of frequent high hand-force exposure (23.2\% at baseline, $22.4 \%$ at 1 year) than the incidence cases $(\mathrm{N}=22)(31.8 \%$ at both baseline and 1 year) throughout the study, although the difference was not statistically significant (table 4).

Right-sided clinical cases and those with only physical findings reported the lowest general health $(\mathrm{P}=0.0005)$. Those with right-sided current symptoms or clinical case status reported lower social support

Table 3. Demographic characteristics of the participants by right shoulder status at baseline $(\mathrm{N}=436) .{ }^{\text {a }}$

\begin{tabular}{|c|c|c|c|c|c|}
\hline Characteristic & $\begin{array}{l}\text { No symptoms } \\
\text { or physical } \\
\text { findings } \\
(\mathrm{N}=298)(\%)\end{array}$ & $\begin{array}{c}\text { Physical } \\
\text { findings without } \\
\text { symptoms } \\
(\mathrm{N}=36)(\%)\end{array}$ & $\begin{array}{c}\text { Past } \\
\text { symptoms } \\
(\mathrm{N}=21) \\
(\%)\end{array}$ & $\begin{array}{c}\text { Current } \\
\text { symptoms } \\
(\mathrm{N}=48) \\
(\%)\end{array}$ & $\begin{array}{c}\text { Clinical } \\
\text { case } \\
(\mathrm{N}=33)\end{array}$ \\
\hline Male (N=215) & 52.7 & 47.2 & 33.3 & 31.3 & 57.6 \\
\hline \multicolumn{6}{|l|}{ Race } \\
\hline $\begin{array}{l}\text { White }(N=251) \\
\text { Asian }(N=88) \\
\text { Hispanic }(N=57) \\
\text { Other }(N=40)\end{array}$ & $\begin{array}{c}58.7 \\
19.1 \\
13.4 \\
8.7\end{array}$ & $\begin{array}{c}61.1 \\
13.9 \\
16.7 \\
8.3\end{array}$ & $\begin{array}{c}42.9 \\
38.1 \\
9.5 \\
9.5\end{array}$ & $\begin{array}{c}56.3 \\
22.9 \\
8.3 \\
12.5\end{array}$ & $\begin{array}{c}54.6 \\
21.2 \\
15.2 \\
9.1\end{array}$ \\
\hline With at least high school education ( $N=364)$ & 82.9 & 83.3 & 81.0 & 91.7 & 78.8 \\
\hline
\end{tabular}

a Median age: 40.3 years for the participants with no symptoms or physical findings, 43.3 years for those with physical findings without symptoms, 37.3 years for those with past symptoms, 43.4 years for those with current symptoms, and 45.7 years for clinical cases.

${ }^{b}$ Median years in current job: 2.3 years for the participants with no symptoms or physical findings, 2.5 years for those with physical findings without symptoms, 2.2 years for those with past symptoms, 4.3 for those with current symptoms, and 3.8 for clinical cases. 
Table 4. Observed exposures by right shoulder status at baseline $(\mathrm{N}=436){ }^{\mathrm{a}}$

\begin{tabular}{|c|c|c|c|c|c|c|c|}
\hline Higher level & $\begin{array}{c}\text { All } \\
\text { participants } \\
\text { attending } \\
1 \text {-year } \\
\text { follow-up } \\
(\mathrm{N}=436) \\
(\%)\end{array}$ & $\begin{array}{c}\text { No } \\
\text { symptoms } \\
\text { or } \\
\text { physical } \\
\text { findings } \\
(\mathrm{N}=298) \\
(\%)\end{array}$ & $\begin{array}{c}\text { Physical } \\
\text { findings } \\
\text { without } \\
\text { symptoms } \\
(\mathrm{N}=36) \\
(\%)\end{array}$ & $\begin{array}{c}\text { Past } \\
\text { symptoms } \\
(\mathrm{N}=21) \\
(\%)\end{array}$ & $\begin{array}{c}\text { Current } \\
\text { symptoms } \\
(\mathrm{N}=48) \\
(\%)\end{array}$ & $\begin{array}{c}\text { Clinical } \\
\text { case } \\
(\mathrm{N}=33) \\
(\%)\end{array}$ & P-value ${ }^{b}$ \\
\hline Upper-arm abduction $>60$ degrees $>7.0 \%$ of the time & 23.6 & 22.5 & 36.1 & 23.8 & 27.1 & 15.2 & 0.29 \\
\hline Upper-arm flexion $>45$ degrees $>4.0 \%$ of the time & 31.0 & 29.2 & 36.1 & 38.1 & 33.3 & 33.3 & 0.81 \\
\hline Lifting, time-weighted average $>44.1 \mathrm{~N}$ & 13.5 & 13.1 & 22.2 & 4.8 & 14.6 & 12.1 & 0.46 \\
\hline Lifting, peak $>66.7 \mathrm{~N}$ & 21.6 & 21.5 & 30.6 & 19.1 & 16.7 & 21.2 & 0.66 \\
\hline Hand exertion duration $>6$ seconds & 22.7 & 24.2 & 19.4 & 14.3 & 18.8 & 24.2 & 0.81 \\
\hline Hand exertion frequency $>20 /$ min & 18.1 & 16.4 & 16.7 & 19.1 & 25.0 & 24.4 & 0.51 \\
\hline Frequency of high forces ${ }^{c}>6 / \mathrm{min}$ & 24.3 & 23.5 & 19.4 & 28.6 & 18.8 & 42.4 & 0.13 \\
\hline
\end{tabular}

a Time-weighted or peak lifting was dichotomized according to published guideline limits, as in appendix B of the Washington State ergonomics rule (19). The cut point for upper-arm abduction, upper-arm flexion, duration of hand exertion, frequency of hand exertion, and high frequency of high force exertions was close to the 75th percentile of these exposure variables.

${ }^{b}$ Chi-square test for the five shoulder status groups, $\alpha=0.05$.

c High forces were defined as $\geq 8.9 \mathrm{~N}$ of the pinch force or object weight (corresponding to $2 \mathrm{lb}$ or $0.9 \mathrm{~kg}$ ) or as $44.1 \mathrm{~N}$ of the power grip, object weight, or push-pull force (corresponding to $10 \mathrm{lb}$ or $4.5 \mathrm{~kg}$ ) according to the Washington State ergonomics rule (19).

Table 5. Psychosocial aspects of the work at baseline for the participants by right shoulder status. (SF12 = 12-item Short-form Health Survey)

\begin{tabular}{|c|c|c|c|c|c|c|c|c|c|c|c|c|c|c|c|c|c|c|c|}
\hline \multirow[t]{2}{*}{ Characteristic } & \multicolumn{3}{|c|}{$\begin{array}{l}\text { All participants } \\
\text { attending } 1 \text {-year } \\
\text { follow-up (N=415) }\end{array}$} & \multicolumn{3}{|c|}{$\begin{array}{l}\text { No symptoms or } \\
\text { physical findings } \\
\quad(\mathrm{N}=286)\end{array}$} & \multicolumn{3}{|c|}{$\begin{array}{c}\text { Physical findings } \\
\text { without symptoms } \\
(\mathrm{N}=34)\end{array}$} & \multicolumn{3}{|c|}{$\begin{array}{l}\text { Past symptoms } \\
\quad(N=20)\end{array}$} & \multicolumn{3}{|c|}{$\begin{array}{l}\text { Current symptoms } \\
\qquad(\mathrm{N}=43)\end{array}$} & \multicolumn{3}{|c|}{$\begin{array}{l}\text { Clinical case } \\
\quad(\mathrm{N}=32)\end{array}$} & \multirow[t]{2}{*}{ P-value ${ }^{a}$} \\
\hline & $\%^{b}$ & $\begin{array}{l}\text { Me- } \\
\text { dian }\end{array}$ & Range & $\%^{b}$ & $\begin{array}{l}\text { Me- } \\
\text { dian }\end{array}$ & Range & $\%^{\mathrm{b}} \mathrm{d}$ & $\begin{array}{l}\text { Me- } \\
\text { dian }\end{array}$ & Range & $\%{ }^{b} \mathrm{~d}$ & $\begin{array}{l}\text { Me- } \\
\text { dian }\end{array}$ & Range & $\%^{b}$ & $\begin{array}{l}\text { Me- } \\
\text { dian }\end{array}$ & Range & $\%^{b}$ & $\begin{array}{l}\text { Me- } \\
\text { dian }\end{array}$ & Range & \\
\hline $\begin{array}{l}\text { High job } \\
\text { demands }\end{array}$ & 62.2 & $\cdot$ & . & 62.2 & . & $\cdot$ & 64.7 & . & . & 50.0 & . & . & 69.5 & $\cdot$ & . & 68.8 & . & $\cdot$ & 0.74 \\
\hline $\begin{array}{l}\text { High decision } \\
\text { latitude }\end{array}$ & 62.7 & $\cdot$ & $\cdot$ & 63.6 & . & $\cdot$ & 76.5 & . & . & 60.0 & $\cdot$ & . & 44.2 & $\cdot$ & . & 65.6 & . & $\cdot$ & 0.0531 \\
\hline $\begin{array}{l}\text { High job } \\
\text { satisfaction }\end{array}$ & 69.2 & $\cdot$ & $\cdot$ & 71.7 & . & . & 76.5 & . & . & 65.0 & $\cdot$ & . & 55.8 & $\cdot$ & . & 59.4 & . & $\cdot$ & 0.14 \\
\hline $\begin{array}{l}\text { High social } \\
\text { support }\end{array}$ & 64.6 & . & . & 67.1 & . & . & 76.5 & . & . & 70.0 & . & . & 41.9 & . & . & 56.3 & . & . & 0.0078 \\
\hline $\begin{array}{l}\text { High job } \\
\text { security }\end{array}$ & 69.9 & $\cdot$ & $\cdot$ & 72.4 & . & . & 64.7 & $\cdot$ & . & 70.0 & . & . & 67.4 & . & . & 56.3 & . & $\cdot$ & 0.38 \\
\hline $\begin{array}{l}\text { High general } \\
\text { health }\end{array}$ & 56.1 & . & . & 61.9 & . & . & 35.3 & . & . & 70.0 & . & . & 44.2 & . & . & 34.4 & . & . & 0.0005 \\
\hline $\begin{array}{l}\text { Physical } \\
\text { health (SF12) }\end{array}$ & d & 48.8 & $0.2-61.8$ & 8 . & 49.6 & $20.2-61.8$ & 3. 4 & 49.7 & $29.8-57.3$ & 3. & 46.7 & $28.5-58.0$ & 0 . & 46.42 & $2.3-55$. & & 44.927 & $.9-54.2<0$ & $<0.0001^{\mathrm{e}}$ \\
\hline $\begin{array}{l}\text { Mental } \\
\text { health (SF12) }\end{array}$ & d & 52.4 & $7.0-63.4$ & 4 . & 52.7 & $18.9-62.7$ & . & 54.0 & $21.6-61.7$ & & 49.8 & $17.0-63.4$ & 4 . & 50.32 & $5.8-61$. & 0 & 52.1 & $6.5-60.0$ & $0.33^{e}$ \\
\hline
\end{tabular}

${ }^{\text {a }}$ Chi-square test, $\alpha=0.05$.

b Percentage greater or equal to median.

c The psychosocial factors were dichotomized on the basis of the median score: job demands (median 3.0, range -4.0-10.0), decision latitude (median 10.0, range -2.0-22.0), social support (median 9.0, range 3.0-12.0), job satisfaction (median 1.0, range -3.0-3.0), job security (median 1.0, range -3.03.0 ), and general health (median 7.0, range 2.0-10.0).

${ }^{d} \mathrm{~N}=375$ for all of the participants attending the 1 -year follow-up, $\mathrm{N}=260$ for those with no symptoms or physical findings, $\mathrm{N}=31$ for those with physical findings without symptoms, $\mathrm{N}=18$ for those with past symptoms, $\mathrm{N}=39$ for those with current symptoms, and $\mathrm{N}=27$ for clinical case.

${ }^{\text {e }}$ Kruskal-Wallis test, $\alpha=0.05$.

$(\mathrm{P}=0.0078)$, and the clinical cases had lower SF-12 physical health scores $(\mathrm{P}=0.0002)$ than those with no symptoms (table 5). The post-hoc nonparametric tests further indicated that there were significant differences at baseline between the asymptomatic participants and the clinical cases with respect to SF-12 physical health $(\mathrm{P}=0.0002)$ and the perception of general health $(\mathrm{P}=0.0027)$.

\section{Natural course of shoulder disorders}

Table 6 summarizes the natural course of the nontraumatic onset shoulder problems in terms of prevalence, incidence, persistence, and recovery rates. The prevalence of shoulder symptoms, physical findings, and clinical cases was higher on the right side than on the left ( $\mathrm{P}<0.0001$ for all comparisons). There were 10 bilateral 
Table 6. Summary table of the prevalence and incidence of rotator cuff tendinitis and shoulder symptoms

\begin{tabular}{|c|c|c|c|c|}
\hline \multirow[t]{2}{*}{ Health outcome } & \multicolumn{2}{|c|}{ Right shoulder } & \multicolumn{2}{|c|}{ Left shoulder } \\
\hline & $\mathrm{N}$ & $\%$ & $\mathrm{~N}$ & $\%$ \\
\hline \multicolumn{5}{|l|}{ Prevalence of shoulder symptoms during the past 12 months a } \\
\hline Total baseline population $(\mathrm{N}=698)$ & 168 & 24.1 & 112 & 16.0 \\
\hline Those of the baseline population who attended the follow-up, baseline value $(\mathrm{N}=436)$ & 102 & 23.4 & 65 & 14.9 \\
\hline 1-year follow-up $(\mathrm{N}=436)$ & 83 & 19.0 & 70 & 16.1 \\
\hline \multicolumn{5}{|l|}{ Prevalence of shoulder symptoms during the past 7 days and 12 months $^{b}$} \\
\hline Total baseline population $(\mathrm{N}=698)$ & 135 & 19.3 & 85 & 12.2 \\
\hline Those of the baseline population who attended the follow-up, baseline value $(\mathrm{N}=436)$ & 81 & 18.6 & 50 & 11.2 \\
\hline 1-year follow-up ( $N=436)$ & 64 & 14.7 & 55 & 12.6 \\
\hline \multicolumn{5}{|l|}{ Prevalence of rotator cuff tendinitis ${ }^{c}$} \\
\hline Total baseline population ( $\mathrm{N}=698)$ & 53 & 7.6 & 35 & 5.0 \\
\hline Those of the baseline population who attended follow-up, baseline value $(\mathrm{N}=436)$ & 33 & 7.6 & 21 & 4.8 \\
\hline 1 -year follow-up ( $N=436)$ & 33 & 7.6 & 19 & 4.4 \\
\hline Incidence of 12-month symptoms [N=334 (right), 371 (left)] & 41 & 12.3 & 44 & 11.9 \\
\hline One-year incidence of clinical stage rotator cuff tendinitis [ $\mathrm{N}=403$ (right), 415 (left)] & 22 & 5.5 & 12 & 2.9 \\
\hline Participants not fulfilling symptom criteria and without physical findings [N=298 (right), 351 (left)] & 6 & 2.0 & 4 & 1.1 \\
\hline Participants with physical findings but not fulfilling symptom criteria [N=36 (right), 20 (left)] & 8 & 22.2 & 4 & 20.0 \\
\hline Participants fulfilling symptom criteria but without physical findings at baseline [ $N=48$ (right), 29 (left)] & 7 & 14.6 & 4 & 13.8 \\
\hline Persistence of 12-month symptoms [N=102 (right), 65 (left)] & 42 & 41.2 & 26 & 40.0 \\
\hline Persistence of clinical stage rotator cuff tendinitis [N=33 (right), 21 (left)] & 11 & 33.3 & 7 & 33.3 \\
\hline Complete recovery from clinical stage rotator cuff tendinitis [N=33(right), 21 (left)] & 13 & 39.4 & 11 & 52.4 \\
\hline
\end{tabular}

a Denotes pain, stiffness, spasm, inability to raise arm, burning, numbness, or tingling with a frequency of at least once a month OR lasting at least 1 week. ${ }^{b}$ Presence of the shoulder problem fulfilling the above 12-month symptom criterion AND shoulder problem during the past 7 days; no additional criterion for intensity, duration, or frequency for the symptoms during the past 7 days.

c Criteria for symptoms as above AND with a positive sign in one of the following tests: resisted shoulder abduction, internal rotation, external rotation, or painful arc (in the provocation test reported, intensity of pain $\geq 1$ on a scale from 0 to 4 ) (17).

clinical cases at baseline and 6 after 1 year. A considerable migration between the various states of shoulder problems was observed during the follow-up of 1 year (figure 1, for the right shoulder). For all five diagnostic categories, the major path was to the no symptom-no physical finding status by 1 year $(88.3 \%)$. There were 22 incident cases $(5.5 \%)$ on the right side, of which 8 were identified at the 4- and 8-month follow-up visits and 14 at the annual visit. Incident cases were present across the sites, both in manufacturing and in health care. The incidence of clinical cases tended to be higher for the right side than for the left $(\mathrm{P}=0.08)$. Those with only symptoms $(\mathrm{P}<0.0001$, right or left $)$ or physical findings $(\mathrm{P}=0.0007$ right, 0.0024 left $)$ at baseline

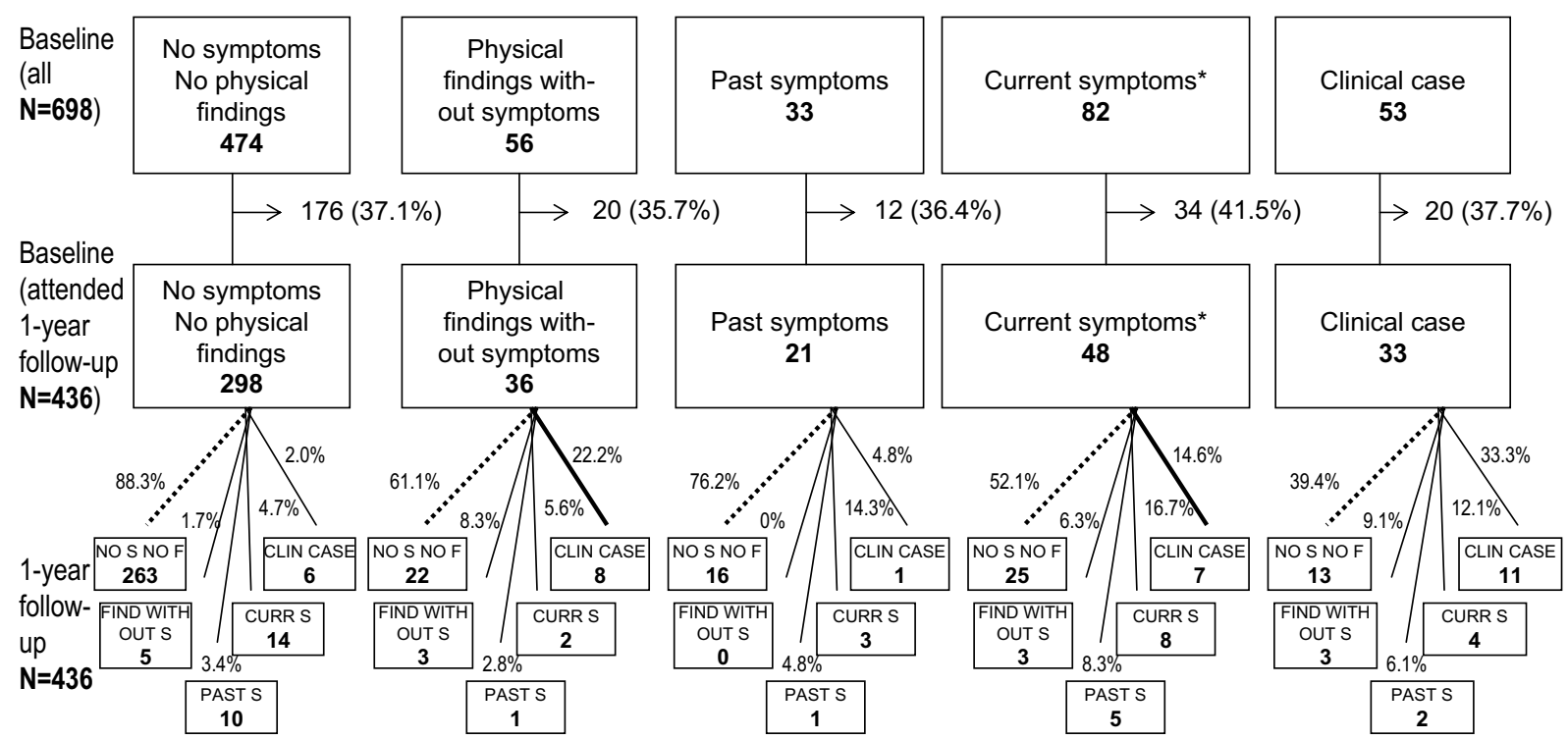

Figure 1. Natural course of nontraumatic rotator cuff tendinitis and other shoulder problems on the right side. $\left({ }^{*}=\right.$ symptoms fulfilling the 12 month and 7-day criteria, $\mathrm{S}=$ symptoms, $\mathrm{F}$ = findings, CLIN = clinical, FIND, findings, CURR = current) 
were much more likely to contract clinical case status within 1 year than those with no symptoms and no physical findings. Three participants with right-shoulder clinical case status at baseline became left-shoulder incident cases at 1 year.

\section{Job changes between the baseline and follow-up}

Of those $(\mathrm{N}=263)$ who were without symptoms and physical findings with regard to their right shoulder throughout the study, $36.9 \%$ reported a job change during the follow-up. A minority (19 participants, 7.2\%) changed physical load category according to the ergonomic assessment. Among the incident cases the corresponding percentages were 50.0 and 13.6. Of the 13 right-sided prevalent cases at baseline with complete recovery, 7 (53.9\%) changed jobs and 5 (38.4\%) changed physical load category. Of the 11 persistent cases, 5 (45.5\%) changed jobs and 3 (27.3\%) changed exposure category. Among the participants who remained without symptoms or physical findings, 19 changed jobs in force ( 7 decreased, 4 increased, and 8 no change) or in repetition (11 decreased, 4 increased, and 4 no change). Among the 3 incident cases with confirmed job changes, 1 changed to lower force and 2 changed to higher repetition before becoming an incident case. Of the 5 recovered cases with job changes confirmed in the ergonomic assessment, 2 decreased in force, 3 decreased in repetition, and 1 increased in repetition. The 3 persistent cases with job changes included 2 decreased in force and 1 decreased in repetition. Thus there was no clear pattern of job change related to the case definitions.

\section{Interference with quality or pace of work, sick leave, and seeking medical advice}

Of the 22 participants who were diagnosed as incident cases in the 1-year follow-up, $22.7 \%$ reported difficulty in maintaining a normal workpace or quality of work, $9.1 \%$ having been on light or restricted duty and $31.8 \%$ having had medical treatment for their shoulder problem. The corresponding proportions for the persistent cases $(\mathrm{N}=11)$ were higher at baseline $(27.3 \%, 36.4 \%$, and $45.5 \%$, respectively) and stayed high at the 1 -year follow-up $(45.5 \%, 36.4 \%$, and $50.0 \%$, respectively). Those who recovered $(\mathrm{N}=13)$ showed some high proportions at baseline with respect to difficulty in maintaining workpace or quality (38.5\%) and having sought medical treatment $(23.1 \%)$, with a major decrease by the 1-year follow-up ( $0.0 \%$ and $7.7 \%$, respectively). Missed workdays were reported by $10(18.2 \%)$ of the 55 participants diagnosed as clinical cases at any time during the study.
The 15 (37.5\%) persistent cases of shoulder symptoms (figure 1) reported having difficulty in maintaining a normal workpace $(40.0 \%$ at baseline, $33.3 \%$ at 1 year) and had medical treatment for the shoulder problem $(33.3 \%$ at baseline, $20.0 \%$ at 1 year), the proportions were comparable to the persistent cases of rotator cuff tendinitis. The proportion having been on light or restricted duty was higher at baseline than in the 1-year follow-up (13.3\% at baseline, $0 \%$ at 1 year).

\section{Discussion}

This descriptive paper followed the natural course of rotator cuff tendinitis and shoulder symptoms in a working population in a variety of industries with different physical and psychosocial risk factors. The vast majority of the participants remained without signs and symptoms of rotator cuff tendinitis. One-year incident cases were relatively infrequent. The only statistical difference between those who were without signs and symptoms versus clinical cases was the exposure to frequent high hand forces at baseline.

As this study shows, case definitions are critical when both the incidence and prevalence of work-related musculoskeletal disorders are estimated. In an effort to identify "nontrivial" shoulder cases and increase the likelihood of participants remembering whether or not they had had an episode in the previous year, we limited the case definition to those with recurring symptoms of nontraumatic origin. The definition of a clinical case of rotator cuff tendinitis in this study is consistent with the physical examination criteria for shoulder tendinitis advocated by Helliwell et al (24) and Sluiter et al (17). However, because our "clinical cases" were still working with pain and physical findings, they may have been more representative of milder rotator cuff tendinitis than clinical case series or worker compensation cases.

The difference in case definition may explain some of the difference generally seen between men and women with musculoskeletal disorders in working populations. In this study there was some evidence of differential reporting of symptoms by gender (higher among the women) while physical findings and clinical cases were more likely among the men (table 3 ). This finding may have implications with respect to the overestimation of risk by gender for case definitions based on symptoms alone. However it does not mean that we should not conduct studies of symptoms alone. As this study shows, recurring symptoms may predict future clinical cases.

Two important limitations of this study were the participation rate $(64.5 \%)$ and the follow-up rate $(62.5 \%)$. The greatest restriction on participation was imposed by 
the production process. While some supervisors actively encouraged participation, many others were more concerned about meeting production needs and therefore discouraged participation. It was extremely difficult to identify the actual number of potentially eligible participants. For some sites, we were limited in the total number of participants that we could have. The second limitation was the economic downturn experienced during the study. It is difficult to estimate how the baseline and follow-up participation rates affected our estimates of the prevalence, incidence, and persistence of shoulder problems. However, the reasons for nonparticipation and nonretention appeared to be mostly production-related and structural. Moreover, our data showed that the proportions of those lost to follow-up did not differ between the different shoulder status groups (figure 1) (ie, we saw no clear health-based selection out of our cohort). Limiting participant selection to those with four or fewer tasks may have eliminated those with infrequent but high shoulder loads such as mechanics or other skilled trade people and thereby caused an underestimation of the effect of high physical shoulder loads.

The incidences of 12-month symptoms on the right $(12.3 \%)$ and left $(11.9 \%)$ side were comparable with the $14 \%$ found by Miranda et al (4) and the 15\% reported by Harkness et al (5) and Luime et al (7). The case definition of Miranda et al (4) was pain on at least 8 days in the past 12 months, that of Harkness (5) was pain at least 1 day in the previous month, and that of Luime (7) was an episode of pain, stiffness, or discomfort at any time during the past 12 months. The study population in the Harkness et al study was considerably younger (median age 23 years) than our study population, and the definition of 12-month symptoms in our study was more stringent than that of Luime et al. Another study with a different design and case definition among computer users in Denmark (8) reported the incidence of shoulder symptoms in the past 12 months by frequency $(18 \%)$ and intensity $(20 \%)$ separately.

Of the participants reporting right-sided 12-month symptoms at baseline, $41 \%$ still had them after 1 year (table 6). This value is lower than the $55 \%$ with persistent symptoms for 12 months reported by Miranda et al (4) and the 54\% reported by Macfarlane et al (1) in a 3year follow-up.

Several incident cases were identified at the 4- and 8-month follow-up rather than at the 1-year follow-up. Moreover, the relatively high proportion of those with persistent symptoms ( $41.2 \%$ and $40.0 \%$, respectively) and persistent clinical rotator cuff tendinitis cases (33.3\% and $33.3 \%$, respectively), as well as those with complete recovery from clinical stage rotator cuff tendinitis (39.4\% and $52.4 \%$, respectively) raises some issues, including appropriate case definitions, incident or episodic designation, frequency of follow-up, and longterm consequences. Bonde et al (12) reported that $50 \%$ of the clinical cases in their study had recovered by roughly 10 months, compared with the 70-75\% recovered by 1 year in our population. Bonde et al (12) did not find that the repetitive work category or psychosocial demands had a significant influence on recovery. However, the follow-up was performed annually, whereas in our study, it was done at 4-month intervals, during which lost worktime and job transfers were frequent.

Of the 12 left-shoulder incident cases at 1 year, three were right-shoulder clinical cases at baseline; this finding suggests that a problem in one shoulder could be a risk factor for the other shoulder. This observation comprises an important implication for prevention. It would be better to treat the original shoulder problem to avoid a second problem on the other side. It is also important to reduce any contributory work factors for both shoulders.

Those with only symptoms or physical findings at baseline were much more likely to develop clinical case status within 1 year than those with neither symptoms nor findings. These results indicate that the surveillance of symptoms among working populations, as well as physical examinations of nonsymptomatic participants, can identify subgroups with a high risk of becoming clinical cases (secondary prevention).

In a clinical population with incident shoulder pain, Croft et al (25) reported that only $21 \%$ had recovered completely at 6 months. Similarly, in a Dutch clinical population, van der Windt et al (26) reported complete recovery from incident cases of shoulder pain for $23 \%$ at 1 month and for 59\% at 1 year. Although our population consisted of active workers not necessarily seeking treatment, $40.6 \%$ of the clinical cases of rotator cuff tendinitis on the right side and $52.6 \%$ on the left had recovered by the time of the 1-year follow-up. It may be that the clinical cases lost to follow-up were more severely affected, but we have no data from which to draw a definite conclusion about this possibility.

Shoulder disorders interfered with work performance or productivity for a notable proportion of the clinical cases, whereas missed workdays were reported fairly infrequently. The relatively high prevalence of reports of interference with workpace or quality due to pain is consistent with that reported by Stewart et al (10) with respect to workers in the United States with musculoskeletal pain and reporting more than 5 hours of lost or reduced productivity per week in the previous 2 weeks. The vast majority was due to reduced performance while at work rather than to work absence.

The clinical cases and the participants with current symptoms had lower proportions of perceived high job security and social support than those with no symptoms 
or physical findings, whereas there was little difference in job satisfaction (table 5). These findings are consistent with those of Nahit et al (27), who reported that high job demands and poor support increased the odds of incident shoulder pain, while job satisfaction was no different in a newly employed population, although our study did not show significant difference in job demand.

Reported job changes were common and as frequent among those who were nonsymptomatic and without physical findings throughout the study as among the incident, recovered, and persistent cases. However, job changes in which the ergonomic assessment confirmed a change in the physical workload category seemed to be more frequent among the incident, persistent, and recovered cases than among those who remained without symptoms and findings. The small number of participants with clinical case status at any time prevented a detailed analysis of the relations between the direction of change in physical loading and the change in diagnostic group. It therefore remains unknown whether the frequent job changes in this population represented an informal means of reducing specific exposures believed to play a role in rotator cuff tendinitis.

In working populations, shoulder problems appear to be frequent and volatile in their course. Those with symptoms or physical findings alone at baseline appear to be more likely to become clinical cases in the course of the preceding year. The comparable proportions of reporting the interference of shoulder problems with work quality among persistent cases of shoulder symptoms and rotator cuff tendinitis suggested that self-reported complaints of shoulder problems should not be ignored. If we are to understand the clinical course of shoulder problems in working populations better, it is imperative that case definitions include specific shoulder location, some estimate of duration and frequency of episodes, and standardized clinical tests. In a followup study, changes in both exposure and health outcome need to be monitored. For example, after all jobs with frequent high hand force have been identified, efforts can be made to reduce the exposure (primary prevention). For those who are symptomatic or have physical findings, efforts should be made to reduce exposure through job modification, and these workers should be monitored closely to prevent further progress of the disorder (secondary prevention). Frequent follow-up will identify incident cases that may be missed with annual follow-up alone.

\section{Acknowledgments}

We acknowledge the important contributions of Peregrin Spielholz, Ninica Howard, and Ruby Irving to the exposure assessment and Dana Wilcox, Sarah West, and Tiffany Ballard to the health assessment.

This research was funded in part by the United States National Institute for Occupational Safety and Health (OH007316) and the Washington State Department of Labor and Industries.

\section{References}

1. Macfarlane GJ, Hunt IM, Silman AJ. Predictors of chronic shoulder pain: a population based prospective study. J Rheumatology. 1998;25:1612-5.

2. Mäkelä M, Heliövaara $M$, Sainio $P$, Knekt $P$, Impivaara $O$, Aromaa A. Shoulder joint impairment among Finns aged 30 years or over: prevalence, risk factors and co-morbidity. Rheumatology (Oxford). 1999;38:656-62.

3. Miranda H, Viikari-Juntura E, Heistaro S, Heliövaara M, Riihimäki H. A population study on differences in the determinants of a specific shoulder disorder versus nonspecific shoulder pain without clinical findings. Am J Epidemiol. 2005;161(9):847-55.

4. Miranda H, Viikari-Juntura E, Martikainen R, Takala EP, Riihimäki H. A prospective study of work related factors and physical exercise as predictors of shoulder pain. Occup Environ Med. 2001;58:528-34.

5. Harkness EF, Macfarlane GJ, Nahit ES, Silman AJ, McBeth J. Mechanical and psychosocial factors predict new onset shoulder pain: a prospective cohort study of newly employed workers. Occup Environ Med. 2003;60:850-7.

6. Svendsen SW, Bonde JP, Mathiassen SE, Stengaard-Pedersen K, Frich LH. Work related shoulder disorder: quantitative exposure-response relations with reference to arm poster. Occup Environ Med. 2004;61:844-53.

7. Luime JJ, Kuiper JI, Kose BW, Verhaar JAN, Miedema H, Burdorf A. Work-related risk factors for the incidence and recurrence of shoulder and neck complaints among nursinghome and elderly-care workers. Scand J Work Environ Health. 2004;30(4):279-86.

8. Juul-Kristensen N, Søgaard k, Strøyer J, Jensen C. Computer users' risk factors for developing shoulder, elbow and back symptoms. Scand J Work Environ Health. 2004;30(5):390-8.

9. Silverstein B, Kalat J, Fan JZ. Work-related musculoskeletal disorders of the neck, back, and upper extremity in Washington State state fund and self-insured workers' compensation claims 1993-2001. Olympia (WA): Washington State Department of Labor and Industries, Safety and Health Assessment and Research for Prevention; 2003. Washington State Technical Report 40-7.

10. Stewart WF, Ricci JA, Chee E, Morganstein D, Lipton R. Lost productive time and cost due to common pain conditions in the US workforce. JAMA. 2003;290:2443-54.

11. van der Windt DA, Thomas E, Pope DP, de Winter AF, Macfarlane G J, Bouter LM, et al. Occupational risk factors for shoulder pain: a systematic review. Occup Environ Med. 2000;57:433-42.

12. Bonde JP, Mikkelsen S, Andersen JH, Fallentin N, Baelum J, Svendsen SW, et al. Prognosis of shoulder tendinitis in repetitive work: a follow up study in a cohort of Danish industrial and service workers. Occup Environ Med [serial on the Internet]. 2003;60(9):[6 pages]. Cited January 2006; available 
from: http://oem.bmijournals.com.

13. American Conference of Governmental Industrial Hygienists (ACGIH). Hand activity level: 2003 TLVs \& BEIs. Cincinnati (O): ACGIH; 1999. p 112-4.

14. Karasek R, Theorell T. Healthy work: stress, productivity, and the reconstruction of working life. New York (NY) Basic Books; 1990.

15. Bigos SJ, Battié MC, Spengler DM, Fisher LD, Fordyce WE, Hansson TH, et al. A prospective study of work perceptions and psychosocial factors affecting the report of back injury. Spine. 1991;16:1-8.

16. Ware Jr JE, Kosinski M, Keller SD. A 12-item short-form health survey: construction of scales and preliminary tests of reliability and validity. Med Care. 1996;34:220-33.

17. Sluiter JK, Rest KM, Frings-Dresen MHW. Criteria document for evaluating the work-relatedness of upper-extremity musculoskeletal disorders. Scand J Work Environ Health. 2001;27 Suppl 1:1-102.

18. Yen TY, Radwin RG. A video-based system for acquiring biomechanical data synchronized with arbitrary events and activities. IEEE Trans Biomed Eng. 1995;42:944-8.

19. Washington State Department of Labor and Industries: WAC 296-62-051. Ergonomics. 2000.

20. Fallentin N, Juul-Kristensen B, Mikkelsen S, Andersen JH,
Bonde JP, Frost P, et al. Physical exposure assessment in monotonous repetitive work - the PRIM study. Scand J Work Environ Health. 2001;27(1):21-9.

21. McAtamney L, Corlett EN. RULA: a survey method for the investigation of work-related upper limb disorders. Appl Ergon. 1993;24:91-9.

22. Hignett S, McAtamney L. Rapid entire body assessment (REBA). Appl Ergon. 2000;31:201-205.

23. SAS Institute. SAS 9.1. Cary (NC): SAS Institute, Inc.

24. Helliwell PS, Bennett RM, Littlejohn G, Muirden KD, Wigley RD. Towards epidemiological criteria for soft-tissue disorders of the arm. Occup Med. 2003;53(5):313-9.

25. Croft P, Pope D, Silman A. The clinical course of shoulder pain: prospective cohort study in primary care. BMJ. 1996;313:601-2.

26. van der Windt DA, Koes BW, Deville W, De Jong BA, Bouter LM. Shoulder disorders in general practice: prognostic indicators of outcome. Br J Gen Pract. 1996;46:519-23.

27. Nahit ES, Hunt IM, Lunt M, Dunn G, Silman AJ, Macfarlane GJ. Effects of psychosocial and individual psychological factors on the onset of musculoskeletal pain: common and sitespecific effects. Ann Rheum Dis. 2003;62:755-60.

Received for publication: 12 April 2005 